\title{
An analytic model of the CSI
}

\author{
J. Iwaszkiewicz ${ }^{1}$ and A. Muc1 ${ }^{1}$
}

${ }^{1}$ Department of Electrical Engineering

Gdynia Maritime University, Poland

Morska St. 81-87 (Poland)

e-mail: j.iwaszkiewicz@we.umg.edu.pl, a.muc@we.umg.edu.pl

\begin{abstract}
A mathematical model of the current source inverter (CSI) operating in uncharacteristic states has been created in order to support research experiments. It permits to define general features of the CSI thanks to analytic expressions of voltage and current waveforms. The model describes the inverter in digital control time domain. It is useful in analysis of the inverter typical behaviour and transients and in designing of control algorithms.
\end{abstract}

Key words. discrete waveforms; current source inverter; digital control time domain; control algorithm.

\section{Introduction}

The starting of modern alternative current inverter steering algorithms is a multi-phase process. Generally, the first phase is a simulation run of the inverter which is steered by a devised algorithm.

In the presented research simulation programs such as TCAD, MATLAB, PSPICE and PLECKS were used. The actual object steered with the inverter and the steering system is presented during the simulations as the virtual object, described by a set of mathematical equations, and is treated as a mathematical model.

The steering algorithm received in conducted simulations is not usually appropriate to be directly transferred to the steering system. The implementation of the devised algorithm in the controller is either impossible or the transferred control algorithm cannot function in real time and is inadequate for the inverter control [1]. The complexity of the algorithm is customarily the reason. The applicative algorithm is a separate program written and devised based on the analysis of simulations' results. Proper algorithm functioning research is piloted on the actual object: in this phase any deficits or errors in the steering code might lead to inverter damage.

The proposed inverter mathematical model facilitates swift simulation conducting and effective algorithm obtaining, which is suitable for direct implementation. This model describes two-level current inverters operating in systems without a neutral conductor and a triangle or star connected load. It allows to build more complex inverter models which can be composed of two or multilevel inverters, for example an AC-DC-AC inverter.

\section{The Three-phase Inverter Model}

The three-phase inverter represents a complex structure consisted of ideal two-state switches. The substitute scheme of the three-phase inverter is presented in Fig. 1. The inverter is built from three branches: A, B, C, which are assigned to particular phases. The corresponding quantities and variables are categorized as: a, b, c respectively. Two most popular versions of the threephase inverter models are presented in Figure 1. The Figure 1a) presents a circuit constructed of six switches: $K a, K a^{\prime}, K b, K b^{\prime}, K c, K c^{\prime}$, whereas in Figure 1b) a circuit built of three switches: $K a, K b, K c$ is shown. Load is connected to three inverter outputs: $S w_{a}, S w_{b}, S w_{c}$. The circuit with six switches imitates the 'physics' of the two-level three-phase inverter. It is necessary to note that only such a construction allows estimation of all states of the three-phase inverter. The simultaneously switching two switches on or off in one branch can only be assessed by the model in Fig. 1a). A simpler in description model in Figure 1b) proved to be more useful for analyzing voltage source inverters (VSI), what resulted in common application and practice. The object of the paper is to analyze the current source inverters (CSI) so, the model 1a) will be well thought-out.

In this research it is assumed that switches' states are defined with numbers 0 or 1 . "Zero" means the inactive state and the switch does not conduct the current, 'one' the active state of the switch when the current conduction id possible. If it is assumed that the successive symbols of the switches: $a, a^{\prime}, b, b^{\prime}, c, c^{\prime}$ adopt values 0 or 1 , the state of the entire inverter can be described with binary numbers $a a^{\prime} b b^{\prime} c c^{\prime}$. The model in Fig. 1a) depicts a sixbit number. Theoretically, 64 states can be characterized by the $a a^{\prime} b b^{\prime} c c^{\prime \prime}$ number, but practically a multitude of these numbers would present emergency states or such states, which applications would be irrational. Notwithstanding, the state described with, for instance, number (111111) 63 would represent a short circuit of all inverter branches, which is customary in engineering practice, or the starting of every switch in the current inverter, which would imply the starting of vector zero. The latter case involves starting both switches in only one branch of the inverter. Three states of the inverter are depicted with the following numbers: $(110000)_{48}$, $(001100)_{12}$ and $(000011)_{3}$. State $(000000)_{0}$ possesses 
a direct reference which presents an inverter, whose every switch has not yet been steered or has been disabled, even though the intermediary circuit is active.

a)

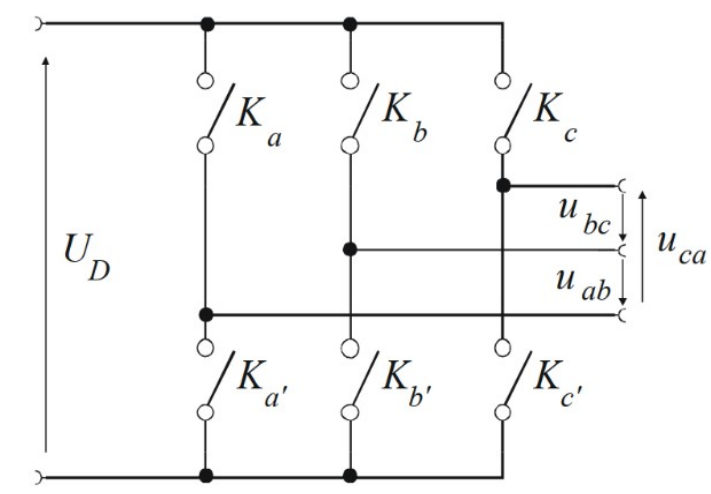

b)

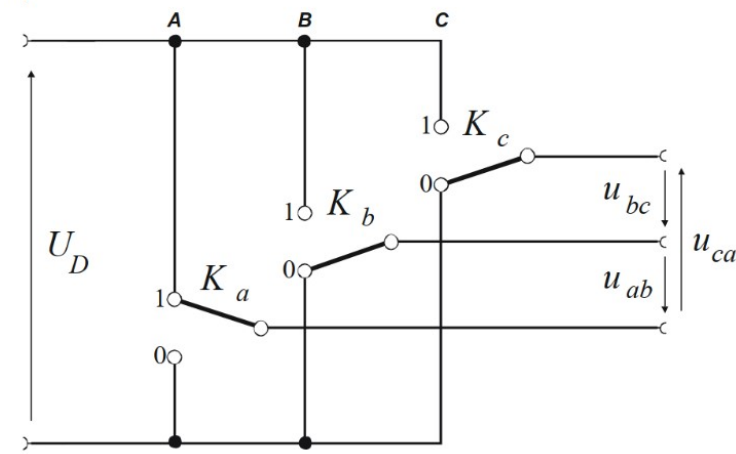

Fig. 1. The most common substitute schema of the inverter: a) model with six two-phase switches, b) model with three switches.

The model in Fig. 1b), as mentioned before, is not appropriate for current source inverter analysis. It's great advantage is the fact that to describe the state of the inverter the three bit number enables depicting all eight inverter states. This model is very useful to analyze VSIs but for analyzing CSI the model in Fig. 1a) is more advantageous and the inverter must be supplied by a current source ID.

For all analyzed models, the following assumptions are in effect: current and voltage waveforms in the figures are treated as positive, switches are presented as two-state lossless switches and switch on and off times equal zero.

\section{Current Source Inverter in Time Domain -Selected States}

To describe the mathematical models of CSIs the converter model from Fig. 1a) has been applied. The operational state of the converter, as mentioned is Chapter2, is characterized by the six-bit binary number .

Decimal numbers (0 to 63) are the decimal equivalents of binary numbers. They depict the subsequent current states in determined inverter phases. These states are called the CSI vectors and are labelled with the symbol. The vector is defined as the three elements row of a matrix (1), where phases currents assume the values presented in Table 1.

$$
\overrightarrow{\mathrm{I}}_{\mathrm{k}}^{\mathrm{t}}=\left\{i_{a k}, i_{b k}, i_{c k}\right\} \text { for } k=0,1,2,3, \ldots, 63
$$

Table 1. Phases currents $i_{a k}, i_{b k}, i_{c k}$ for selected current inverter vectors.

\begin{tabular}{|l|r|r|r|r|r|r|r|r|r|}
\hline $\overrightarrow{\mathrm{I}}_{\mathrm{k}}^{\mathrm{t}}$ & $\overrightarrow{\mathrm{I}}_{3}^{\mathrm{t}}$ & $\overrightarrow{\mathrm{I}}_{12}^{\mathrm{t}}$ & $\overrightarrow{\mathrm{I}}_{48}^{\mathrm{t}}$ & $\overrightarrow{\mathrm{I}}_{6}^{\mathrm{t}}$ & $\overrightarrow{\mathrm{I}}_{9}^{\mathrm{t}}$ & $\overrightarrow{\mathrm{I}}_{18}^{\mathrm{t}}$ & $\overrightarrow{\mathrm{I}}_{24}^{\mathrm{t}}$ & $\overrightarrow{\mathrm{I}}_{33}^{\mathrm{t}}$ & $\overrightarrow{\mathrm{I}}_{36}^{\mathrm{t}}$ \\
\hline$i_{a k}$ & 0 & 0 & 0 & 0 & 0 & $-I_{D}$ & $-I_{D}$ & $I_{D}$ & $I_{D}$ \\
\hline$i_{b k}$ & 0 & 0 & 0 & $-I_{D}$ & $I_{D}$ & 0 & $I_{D}$ & 0 & $-I_{D}$ \\
\hline$i_{c k}$ & 0 & 0 & 0 & $I_{D}$ & $-I_{D}$ & $I_{D}$ & 0 & $-I_{D}$ & 0 \\
\hline
\end{tabular}

Table 1 contains only such active and zero vectors $k=3,6,9,12,18,24,33,36,48$, which occur in abnormal or fault-free operational states of the CSI.

The introduced definition of the current vector has to be applied in the time domain because it operates on physical currents.

\section{A. Current Source Inverter Model - Load Connected in a Star}

The substitute system of the three-phase CSI is presented in Figure 2. The parameter which distinguishes the inverter is the constant value of the intermediary circuit current ID. The discussed inverter load has been connected in a star.

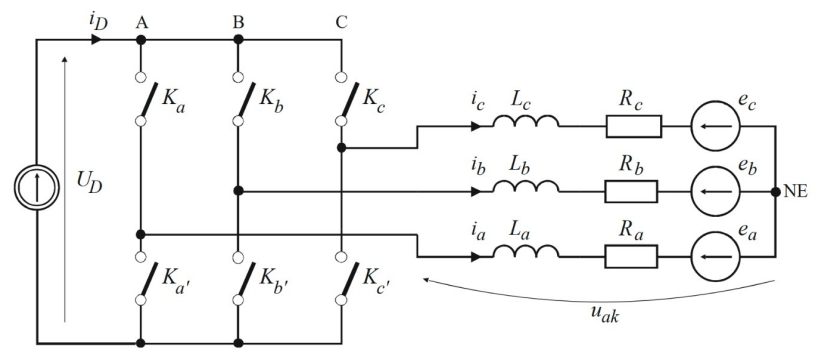

Fig. 2. The current inverter model with $R, L, S E M$ load.

The switches $K a, K a^{\prime}, K b, K b^{\prime}, K c, K c^{\prime}$ depending on the selected current vector, connect the intermediary circuit current $I_{D}$ to selected load branches. It is assumed that there is an ideal source of direct current $I_{D}$ in the intermediary circuit, as well as phases load is symmetrical.

For any current vector $\overrightarrow{\mathbb{I}}_{\mathrm{k}}^{\mathrm{t}}$, starting at the time point $t=T_{n}$, the three-phase inverter model is determined by one closed loop substitute circuit. It was assumed that the phase $c$ load has not been connected to the current source. Figure 3 presents an example of a circuit developed when the $\overrightarrow{\mathrm{I}}_{36}^{\mathrm{t}}$ vector relays to the inverter state.

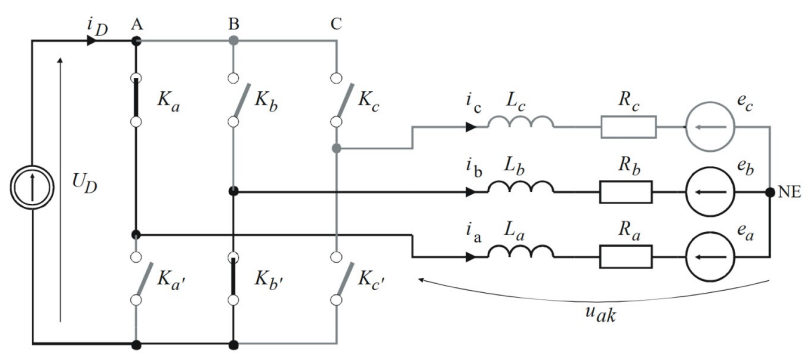

Fig. 3. The substitute current inverter circuit after starting the $\overrightarrow{\mathrm{I}}_{36}^{\mathrm{t}}$ vector. 
For all vectors evaluated in Table 1 phase voltages are expressed by the following equations:

$$
\left.\begin{array}{l}
u_{a_{k}}(t)=R_{a} \cdot I_{D}+L_{a} \frac{d I_{D}}{d t}+e_{a}(t) \text { for } k=33,36 \\
u_{a_{k}}(t)=-R_{a} \cdot I_{D}-L_{a} \frac{d I_{D}}{d t}+e_{a}(t) \text { for } k=18,24 \\
u_{a_{k}}(t)=e_{a}(t) \text { for } k=6,9 \\
u_{b_{k}}(t)=R_{b} \cdot I_{D}+L_{b} \frac{d I_{D}}{d t}+e_{b}(t) \text { for } k=9,24 \\
u_{b_{k}}(t)=-R_{b} \cdot I_{D}-L_{b} \frac{d I_{D}}{d t}+e_{b}(t) \text { for } k=6,36 \\
u_{b_{k}}(t)=e_{b}(t) \text { for } k=18,33 \\
u_{c_{k}}(t)=R_{c} \cdot I_{D}+L_{c} \frac{d I_{D}}{d t}+e_{c}(t) \text { for } k=6,18 \\
u_{c_{k}}(t)=-R_{c} \cdot I_{D}-L_{c} \frac{d I_{D}}{d t}+e_{c}(t) \text { for } k=9,33 \\
u_{c_{k}}(t)=e_{c}(t) \text { for } k=24,36
\end{array}\right\}
$$

In the ideal model the switch on and off times equal $t_{\text {on }}=0$ and $t_{\text {off }}=0$. As a consequence, in equation solutions and results (1) Dirac's delta function appears. This function is labelled with $\delta(t)$, while the expressions of phase voltage take the form of dependencies (2), (3) and (4).

\section{Phase $a$ voltage:}

$$
\begin{aligned}
& u_{a_{k}}(t)=R_{a} \cdot I_{D}+\eta \cdot \sigma\left(t-T_{n}\right)+e_{a}\left(T_{n}\right) \text { for } k=33,36 \\
& \left.\begin{array}{l}
u_{a_{k}}(t)=-R_{a} \cdot I_{D}-\eta_{i} \cdot \sigma\left(t-T_{n}\right)+e_{a}\left(T_{n}\right) \text { for } k=18,24 \\
u_{a_{k}}(t)=e_{a}\left(T_{n}\right) \text { for } 6,9
\end{array}\right\} \text { for } \iota=T_{n} \\
& u_{a_{k}}(t)=R_{a} \cdot I_{D} \mid e_{a}(t) \text { for } k=33,36 \\
& \left.\begin{array}{l}
u_{a_{k}}(t)=-R_{a} \cdot I_{D}+e_{a}(t) \text { for } k=18,24 \\
u_{a_{k}}(t)=e_{a}(t) \text { for } k=6,9
\end{array}\right\} \quad \text { for } T_{n}<t<T_{n+1} \\
& u_{a_{k}}(t)=R_{a} \cdot I_{D}+\eta \cdot \sigma\left(t-T_{n+1}\right)+e_{a}\left(T_{n+1}\right) \text { for } k=33,36 \\
& \left.\begin{array}{l}
u_{a_{k}}(t)--R_{a} \cdot I_{D}-\eta \cdot \sigma\left(t-T_{n+1}\right)+e_{a}\left(T_{n+1}\right) \text { for } k-18,24 \\
u_{a_{k}}(t)=e_{a}\left(T_{n+1}\right) \text { for } 6,9
\end{array}\right\} \text { for } t=T_{n+1}
\end{aligned}
$$

Phase $b$ voltage:

$$
\begin{aligned}
& u_{D_{k}}(t)-R_{b} \cdot I_{D}+\eta \cdot \sigma\left(t-T_{n}\right)+e_{b}\left(T_{n}\right) \text { for } k-9,24 \\
& \left.\begin{array}{l}
u_{b_{k}}(t)=-R_{b} \cdot I_{D}-\eta \cdot \sigma\left(t-T_{n}\right)+e_{b}\left(T_{n}\right) \text { for } k=6,36 \\
u_{b_{k}}(t)=e_{b}\left(T_{n}\right) \text { for } k=18,33
\end{array}\right\} \quad \text { for } t=T_{n} \\
& u_{b_{k}}(t)=R_{b} \cdot I_{D}+e_{b}(t) \text { for } k=9,24 \\
& \left.u_{b_{k}}(t)=-R_{b} \cdot I_{D}+e_{b}(t) \text { for } k=6,36\right\} \quad \text { for } T_{n}<t<T_{n+1} \\
& u_{\nu_{k}}(t)=e_{\nu}(t) \text { for } k=18,33 \\
& u_{L_{k}}(t)=R_{b} \cdot I_{D}+\eta \cdot \sigma\left(t-T_{n+1}\right)+e_{b}\left(T_{n+1}\right) \text { for } k=9,24 \\
& \left.\begin{array}{l}
u_{b_{k}}(t)=-R_{b} \cdot I_{D}-\eta \cdot \sigma\left(t-T_{n+1}\right)+e_{b}\left(T_{n+1}\right) \text { for } k=6,36 \\
u_{b_{k}}(t)=e_{b}\left(T_{n+1}\right) \text { for } k=18,33
\end{array}\right\} \text { for } t=T_{n+1}
\end{aligned}
$$

Phase $c$ voltage:

$$
\begin{aligned}
& u_{c_{k}}(t)=R_{c} \cdot I_{D}+\eta \cdot \sigma\left(t-T_{n}\right)+e_{c}\left(T_{n}\right) \text { for } k=6,18 \\
& \left.u_{c_{k}}(\iota)=-R_{c} \cdot I_{D}-\eta \cdot o\left(\iota-T_{n}\right)+e_{c}\left(T_{n}\right) \text { for } k=9,33\right\} \quad \text { for } t=T_{n} \\
& u_{c_{k}}(t)-e_{c}\left(T_{n}\right) \text { for } k-24,36 \\
& u_{c_{k}}(t)=R_{c} \cdot I_{D}+e_{c}(t) \text { for } k=6,18 \\
& \left.u_{c_{k}}(t)=-R_{c} \cdot I_{D}+e_{c}(t) \text { for } k=9,33\right\} \quad \text { for } T_{n}<t<T_{n+1} \\
& u_{c_{k}}(t)=e_{c}(t) \text { for } k=24,36 \\
& u_{c_{k}}(t)=R_{c} \cdot I_{D}+\eta \cdot \sigma\left(t-T_{n+1}\right)+e_{c}\left(T_{n+1}\right) \text { for } k=6,18 \\
& \left.\begin{array}{l}
u_{c_{k}}(l)=-R_{c} \cdot I_{D}-\eta \cdot o\left(\iota-T_{n+1}\right)+e_{c}\left(T_{n+1}\right) \text { for } k=9,33 \\
u_{c_{k}}(t)-e_{c}\left(T_{n+1}\right) \text { for } k-24,36
\end{array}\right\} \text { for } t=T_{n+1}
\end{aligned}
$$

The coefficient $\eta$ in expressions $2 \ldots 4$ is the product of $L_{a, b, c}$ and $I_{D}$ has dimension [V]. Function $\delta(t)$ replicates an infinite overvoltage when the current source is switched on to the inductive load.

In the real system of the current inverter, the current switching on and off process takes place in a finite time interval. The current $I_{D}$ is switched on, flowing through the $R, L, S E M$ load and switched off. This process can be described taking into account the following assumptions:

- the considered $T_{n}<t<T_{n+1}$ time interval between consequent $\overrightarrow{\mathrm{I}}_{\mathrm{k}(\mathrm{n})}^{\mathrm{t}}$ vector switching. The current flows through the $R, L, e_{f}$ load,

- the turn on process starts at the time point $t=T_{n}$ and occurs during $t=t_{\text {on }}$ time, which is called the turn on time,

- the current increases linearly from the $i\left(T_{n}\right)=0$ value to the $i\left(T_{n}+t_{\text {on }}\right)=I_{D}$ value,

- in the $T_{n}+t_{\text {on }} \leq t \leq T_{n+1}-t_{\text {off }}$ time interval the maintained current value is $i(t)=I_{D}$,

- the turn off process starts at the time point $t=T_{n+1}-t_{\text {off }}$ and takes place in the $t=t_{\text {off }}$ time, which is called the turn off time,

- the current decreases linearly from the $i\left(T_{n+1}-t_{\text {off }}\right)=I_{D}$ value to the $i\left(T_{n+1}\right)=0$.

Taking into consideration aforementioned assumptions, equations' solutions describe the phases voltage waveforms in consequent time periods $T:\left\langle T_{n}, T_{n}+t_{\text {on }}\right\rangle,\left\langle T_{n}+t_{\text {on }}, T_{n+1}-t_{\text {off }}\right\rangle$ and $<T_{n+1}-t_{\text {off }}, T_{n+1}>$. For example, the solutions of the equation (3) for phase $a$ and consequent vectors take the form of expressions:

$$
\begin{aligned}
& \left.\begin{array}{l}
u_{a_{k}}(t)=R_{a} \cdot I_{D}+\frac{L_{a} \cdot I_{D}}{t_{o n}}+e_{a}(t) \text { for } k=33,36 \\
u_{a_{k}}(t)=-R_{a} \cdot I_{D}-\frac{I_{a} \cdot I_{D}}{t_{\text {un }}}+e_{a}(t) \text { for } k=18,21
\end{array}\right\} \quad T_{n} \leq t \leq T_{n}+t_{\text {on }} \\
& u_{a_{k}}(t)=c_{a}(t) \text { for } 6,9 \\
& u_{a l_{k}}(l)=R_{a} \cdot I_{D}+e_{a}(l) \text { for } k=33,36 \\
& \left.u_{a_{k}}(l)=-R_{a} \cdot I_{D}+e_{a}(l) \text { for } k=18,24\right\} \quad T_{n}+t_{\text {on }}<t<T_{n+1}-t_{\text {off }} \\
& u_{a_{k}}(t)=e_{a}(t) \text { for } k=6,9 \\
& u_{a_{k}}(t)-R_{a} \cdot I_{D}+\frac{L_{a} \cdot I_{D}}{t_{u f f}}+e_{a}(t) \text { for } k-33,36 \\
& \left.\begin{array}{l}
u_{a_{k}}(t)=-R_{a} \cdot I_{D}-\frac{L_{a} I_{D}}{t_{\text {off }}}+e_{a}(t) \text { for } k=18,24 \\
u_{a_{k}(t)}=e_{a}(t) \text { for } 6,9
\end{array}\right\} \quad T_{n+1}-t_{\text {off }} \leq t \leq T_{n+1}
\end{aligned}
$$

Analogously, repeating the same pattern as in phase $\boldsymbol{a}$, it is possible to define the expressions for phases voltages $u_{b k}$ and $u_{c k}$. Factors $\frac{L_{a} I_{D}}{t_{\text {on }}}$ and $\frac{L_{a} I_{D}}{t_{\text {off }}}$ in the above expressions (5) express, approximately, the value of overvoltage in real phase voltage waveforms. The example of phase voltage waveform $u_{a k}$, illustrating the transitional processes in the time interval $\left\langle T_{n}, T_{n+1}\right\rangle$ after turning on and off the $\overrightarrow{\mathrm{I}}_{33}^{\mathrm{t}}(\mathbf{1 0 0 0 0 1 )}$ vector is presented in Figure 4. The similar waveforms one can obtain by use of the $\overrightarrow{\mathrm{I}}_{36}^{\mathrm{t}}(100100)$ vector.

The phase-to-phase voltage equations for the selected $\overrightarrow{\mathrm{I}}_{\mathrm{k}}^{\mathrm{t}}$ vector is determined using adequate phases equations.

For vector $\overrightarrow{\mathrm{I}}_{36}^{\mathrm{t}}$ voltage $u_{a b 36}$ is determined from equation (7). 


$$
\begin{gathered}
\mathrm{u}_{\mathrm{ab}_{36}}(t)-\mathrm{u}_{\mathrm{a}_{36}}(t)-\mathrm{u}_{\mathrm{b}_{36}}(t)-\left(\mathrm{R}_{\mathrm{a}}+\mathrm{R}_{\mathrm{b}}\right) \cdot \mathrm{I}_{D} \\
+\left(\mathrm{L}_{\mathrm{a}}+\mathrm{L}_{\mathrm{b}}\right) \frac{\mathrm{dI}_{D}}{\mathrm{dt}}+\mathrm{c}_{\mathrm{a}}(\mathrm{t})-\mathrm{c}_{\mathrm{b}}(\mathrm{t})
\end{gathered}
$$

The solution of this equation is received by utilizing appropriate expressions from (4) and (5).

$$
\begin{gathered}
\mathrm{u}_{\mathrm{ab}_{36}}(\mathrm{t})=\left(\mathrm{R}_{\mathrm{a}} \mid \mathrm{R}_{\mathrm{b}}\right) \cdot \mathrm{I}_{D}\left|2 \eta \cdot \sigma\left(t \quad T_{n}\right)\right| \mathrm{e}_{\mathrm{a}}\left(T_{n}\right) \quad \mathrm{e}_{\mathrm{b}}\left(T_{n}\right) \\
\text { where } t=T_{n} \\
\mathrm{u}_{\mathrm{ab}_{36}}(\mathrm{t})-\left(\mathrm{R}_{\mathrm{a}}+\mathrm{R}_{\mathrm{b}}\right) \cdot \mathrm{I}_{D}+\mathrm{e}_{\mathrm{a}}\left(T_{n}\right)-\mathrm{e}_{\mathrm{b}}\left(T_{n}\right) \\
\text { where } T_{n} \leq \iota \leq T_{n+1} \\
\mathrm{u}_{\mathrm{ab}_{36}}(\mathrm{t})=\left(\mathrm{R}_{\mathrm{a}}+\mathrm{R}_{\mathrm{b}}\right) \cdot \mathrm{I}_{D}-2 \eta \cdot \sigma\left(t-T_{n}\right)+\mathrm{e}_{\mathrm{a}}\left(T_{n}\right)-\mathrm{e}_{\mathrm{b}}\left(T_{n}\right) \\
\text { wheret }=T_{n+1}
\end{gathered}
$$

The same way permits to obtain phase-to-phase voltage for consecutive current vectors as well as phase-to-phase voltage $u_{b c}$ and $u_{c a}$.

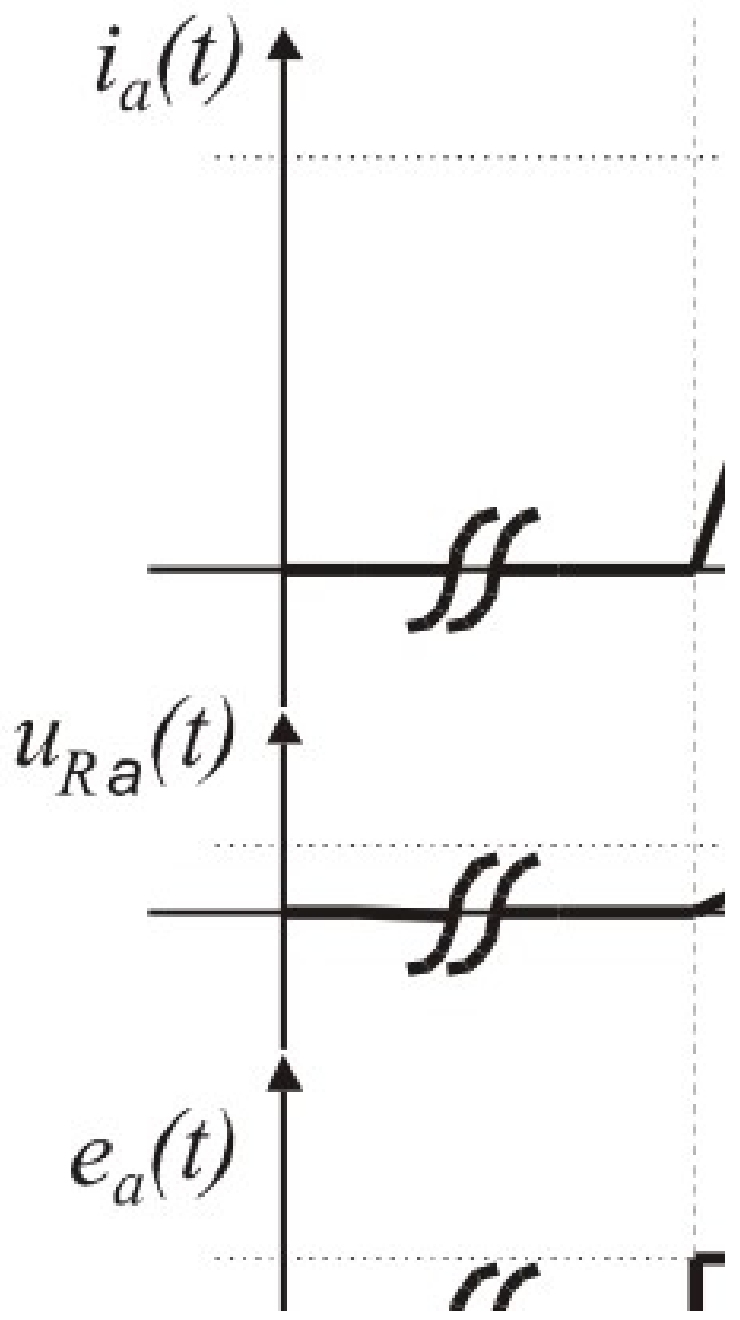

Fig. 4. $u_{a k}$ phase voltage course after starting and disabling the $\overrightarrow{\mathrm{I}}_{33}^{\mathrm{t}}$ vector or the $\overrightarrow{\mathrm{I}}_{36}^{\mathrm{t}}$ vector.

\section{B. The Intermediary Circuit Voltage}

The intermediary circuit voltage $U_{D}$ is easily determined by use of phase-to-phase voltages, since in the current inverter, regardless of the load configuration, voltage $U_{D}$ is always correspondent to one phase-to-phase voltage. For the next current vectors, voltage $U_{D}$ is calculated from the phase-to-phase voltage displayed in Table 2.

Table 2 . The intermediary circuit voltage for certain current vectors

\begin{tabular}{|l|l|l|l|l|l|l|l|l|l|}
\hline $\overrightarrow{\mathrm{I}}_{\mathrm{k}}^{\mathrm{t}}$ & $\overrightarrow{\mathrm{I}}_{3}^{\mathrm{t}}$ & $\overrightarrow{\mathrm{I}}_{12}^{\mathrm{t}}$ & $\overrightarrow{\mathrm{I}}_{48}^{\mathrm{t}}$ & $\overrightarrow{\mathrm{I}}_{6}^{\mathrm{t}}$ & $\overrightarrow{\mathrm{I}}_{9}^{\mathrm{t}}$ & $\overrightarrow{\mathrm{I}}_{18}^{\mathrm{t}}$ & $\overrightarrow{\mathrm{I}}_{24}^{\mathrm{t}}$ & $\overrightarrow{\mathrm{I}}_{33}^{\mathrm{t}}$ & $\overrightarrow{\mathrm{I}}_{36}^{\mathrm{t}}$ \\
\hline$U_{D}$ & $\mathbf{0}$ & $\mathbf{0}$ & 0 & $-U_{b c}$ & $U_{b c}$ & $U_{c a}$ & $-U_{a b}$ & $-U_{c a}$ & $U_{a b}$ \\
\hline
\end{tabular}

\section{A Unified Current Inverter Model with Load Connected in a Star (MFPG)}

To describe the CSIM (CSI Model), understanding of the intermediary circuit current, the selected current vector, time and moment of starting as well as load parameters are fundamental. In the brace bracket all the essential independent variables have been placed.

$$
\text { CSIM }=\left\{I_{D}, \overrightarrow{I_{k}^{t}}, Z_{f}, E_{f}, \mathrm{~T}_{\mathrm{n}} \leq \mathrm{t} \leq \mathrm{T}_{\mathrm{n}+1}\right\}
$$

Other important for the description parameters are determined in the following manner:

- phase voltage $\mathrm{u}_{\mathrm{ak}}(\mathrm{t}), \mathrm{u}_{\mathrm{bk}}(\mathrm{t}), \mathrm{u}_{\mathrm{ck}}(\mathrm{t})$ from the equations $(3,4,5)$,

- phase-to-phase voltage: $\mathbf{u}_{\mathrm{ab}}(\mathrm{t}),-$ from equation $(7,8)$, and $\mathrm{u}_{\mathrm{bc}}(\mathrm{t})$ wed as well as $\mathrm{u}_{\mathrm{ca}}(\mathrm{t})$ according to the rule described in equations (7) and (8),

- intermediary circuit voltage from Table 2 .

If in the ideal model of the current inverter the real turn on and off times of switches are considered, the phases voltages $\mathrm{u}_{\mathrm{ak}}(\mathrm{t})$ can be determined from equations (8), while phases voltages $\mathbf{u}_{\mathrm{bk}}(\mathrm{t})$ and $\mathrm{u}_{\mathrm{ck}}(\mathrm{t})$ - progressing analogously to the procedures described for phase $a$.

\section{Conclusion}

The paper presents a very simple analytic model of the CSI as well as a mathematical system of notation and formulas. The current states of the current source inverter may be defined by use of definite state vectors. The equations describing voltage and current are easy-to-use mathematical tools. They permit to select suitable vector sequence assuring the desirable voltage and current waveform. Thus, they facilitate to design control algorithms of CSIs and particularly current control of AC drives. This mathematical tool was verified during simulation and experimental tests. The considered method could be advanced to other multiphase and multilevel current inverters.

\section{Acknowledgement}

The project financed within the program of the Ministry of Science and Higher Education called "Regionalna Inicjatywa Doskonałości" in the years 2019-2022, the project number $006 / \mathrm{RID} / 2018 / 19$, the sum of financing 11870000 PLN. 


\section{References}

[1] M. Malinowski, K. Gopakumar, J. Rodriguez, M.A.Perez, A Survey on Cascaded Multilevel Inverters. IEEE Trans. Ind. Electron. 2010, 57, pp. 2197-2206.

[2] Y. Li, Y. Wang, B.Q. Li, Generalized Theory of PhaseShifted Carrier PWM for Cascaded H-Bridge Converters and Modular Multilevel Converters. IEEE J. Emerg. Sel. Top. Power Electron. 2016, 4, 2.

[3] A. Łebkowski, Analysis of the Use of Electric Drive Systems for Crew Transfer Vessels Servicing Offshore Wind Farms. Energies 2020, 13, 1466, doi:10.3390/en13061466.

[4] A. Łebkowski, Studies of energy consumption by a city bus powered by a hybrid energy storage system in variable road conditions. Energies 2019, 12, 951, doi:10.3390/en12050951.

[5] Z. Gao, Q. Lu, A hybrid cascaded multilevel converterbased on three-level cells for battery energy management applied in electric vehicles. IEEE Trans. Power Electron. 2018, 34, 73267349, doi:10.1109/TPEL.2018.2882851.

[6] S. Moinoddin, A. Iqbal, H, Abu-Rub, M.R. Khan, S.M.Ahmed, Three-Phase to Seven-Phase Power Converting Transformer. IEEE Trans. Energy Convers. 2012, $27,3$.

[7] D. Lauria, G. Mazzanti, S. Quaia, Some modeling problems for four-phase power transmission systems. In Proceedings of the International Conference on Clean Electrical Power (ICCEP), IEEE Xplore, Ischia, Italy, 14-16 June 2011, doi:10.1109/ICCEP.2011.6036281.
[8] K.T. Chau, C.C. Chan, C. Liu, Overview of permanentmagnet brushless drives for electric and hybrid electric vehicles. IEEE Trans. Ind. Electron. 2008, 55, pp. 2246-2257.

[9] L.Parsa, H. Toliyat, Five-Phase Permanent Magnet Motor Drives. IEEE Trans. Ind. Application S 2005, 41, pp. 30-37.

[10] M. Ruba, F. Surdu, L. Szabo, Study of a Nine-Phase Fault Tolerant Permanent Magnet Starter-Alternator. J. Comput. Sci. Control Syst. 2011, 4, pp. 149-154.

[11] E. Levi, Multiphase Electric Machines for Variable-Speed Applications. IEEE Trans. Ind. Electron. 2008, 55, 1893-1909.

[12] B. Vafakhah, J. Salmon, A.M. Knight, A New SpaceVector PWM with Optimal Switching Selection for Multilevel Coupled Inductor Inverters. IEEE Trans. Ind. Electron. 2010, 57, pp. 2354-2364

[13] N. Celanovic, D. Boroyevich, A Fast Space-Vector Modulation Algorithm for Multilevel Three Phase Converters. IEEE Trans. Ind. Application S 2001, 37, 637-641.

[14] A. Łebkowski W. Koznowski, Analysis of the use of electric and hybrid drives on swath ships. Energies, vol. 13(issue 24): art. no. 6486, s.1, 2020.

[15] M. Rybczak and A. Rak. Prototyping and simulation environment of ship motion control system. TransNav - The International Journal on Marine Navigation and Safety of Sea Transportation, vol. 14(no. 2), pp. 367, 2020.

[16] P. Mysiak. Suppression of supply current harmonics of 18pulse diode rectifier by series active power filter with lc coupling. Energies, vol. 13(issue 22): art. no. 6060, s. 1, 2020. 